\title{
Price Links between Auction and Direct Sales of Fresh and Frozen Fish in North Norway (1997-2003)
}

\author{
KJETIL HELSTAD \\ TERJE VASSDAL \\ TORBJØRN TRONDSEN \\ University of Troms $\varnothing$ \\ JAMES A. YOUNG \\ University of Stirling
}

\begin{abstract}
In North Norway the dominant method of exchange for fresh and frozen fish at the ex-vessel level is by direct (contract) sale, whereby price is negotiated between fish processors and the fishermen. More recently, an auction for frozen fish has been introduced. In this paper we investigate the relationship of prices between these methods of exchange and, in particular, whether the prices develop in a stable pattern between auction and direct sale by means of a cointegration analysis. Monthly prices of size-graded cod and haddock landed in the period 1997-2003 are analysed. For most months, frozen fish sold through auctions realised the highest price, followed by direct sales of fresh and frozen, respectively. Fish sold by auction exhibits a larger monthly variation in price than fish sold directly. Prices for cod were cointegrated to a larger degree than for haddock, and the cointegration was strongest for frozen cod. The analysis also demonstrates that the auction prices for frozen cod and haddock drive the direct sale prices of similar fish, both frozen and fresh, even though the quantity sold via direct sales is greater than that of auctions. Law of one price $(L O P)$ and weak exogeneity were present for cod and haddock.
\end{abstract}

Key words Market linkages, cointegration, auction sale, direct sale, fresh fish, frozen fish, cod, haddock, North Norway.

JEL Classification Codes Q22, C32, D44.

\section{Introduction}

Many fisheries are characterised by low profitability, and a common reason for this status is declining catches from overfished stocks. There is a large literature on methods to improve profitability in fisheries (Anderson 1986; Clark 1990;

Kjetil Helstad is a researcher at the Norwegian College of Fishery Science, University of Troms $\varnothing$, N9037 Troms $\varnothing$, Norway, email: kjetil.helstad@tromsfylke.no. Terje Vassdal is a professor of Business Administration at the Norwegian College of Fishery Science, University of Troms $\varnothing$, email: Terje.Vassdal@nfh.uit.no. Torbjørn Trondsen is a professor of Fish Marketing at the Norwegian College of Fishery Science, University of Troms $\varnothing$, email: torbjorn@ @nfh.uit.no. James. A. Young is a professor of Applied Marketing at the Department of Marketing, University of Stirling, Stirling, FK9 4LA Scotland, email: j.a.young@stir.ac.uk.

This research was supported by the Norwegian Research Council Grant No. 147446/110 and the cooperation of Norges Råfisklag, for which we remain grateful. We thank the following for their valuable comments and support: Frank Asche, Espen Sirnes, and Trygve Myrvang, and others at Norges Råfisklag. 
Hannesson 1993). Introducing restrictions in effort, catches, or some combination of both can increase profitability. Most of this literature is focused upon raising profitability in the long run by improving the regulation regime and reducing catch effort. The literature demonstrating how to increase profitability in the fishery by increasing the unit price (or value) of fish by market-oriented regulations is scarcer. Trondsen and Johnston (1998) show that the possibilities for value adding in the fishing industry are dependent on raw material control, and they argue that fish auctions represent one way to add value if the processors do not control raw material quotas. This paper analyses the effect of such fish auctions on market prices by means of two mechanisms. First, auctions are supposed to be a more informationefficient market organisation than a market with a regulated floor price. Second, auction markets will force buyers to reveal their maximum willingness to pay better than the existing direct sales system.

The importance of raw material control is supported by Ottesen and Grønhaug (2002), who show that uncertainty in the supply of fish is a critical element in Norwegian fish processors' definition of market orientation. Dreyer et al. (1998) showed that 50 of the 75 Norwegian fish processing firms analysed had invested in vessels, yet only four of these got more than $50 \%$ of their supply from their own vessels. The introduction of regulatory measures to reduce fishing effort often causes political controversy, because in many cases, some effort has to leave the fishery or everyone has to share reduced quota. However, despite this fundamental, underpinning role of value, price has not received as much attention as it might have within the literature. A major exception has been the study of cointegration of prices in fish markets. Cointegration analysis is used to analyse relationships between nonstationary time series price data. The method has become the most commonly used for testing market integration and presence of Law of One Price (LOP) (Ardeni 1989; Asche, Bjorndal, and Young 2001; Asche, Salvanes, and Steen 1997; Gordon and Hannesson 1996). Indeed, several empirical analyses of price linkages at different levels in the seafood marketing chain using cointegration analysis have been published recently (Asche, Bremnes, and Wessells 1999; Clayton and Gordon 1999; Jaffry, Pascoe, and Robinson 1999; Asche 2001; Asche et al. 2002). There is also a substantial literature dealing with the theory of stationarity, cointegration, and tests for LOP and weak exogeneity (Muscatelli and Hurn 1992; Maddala and Kim 1998; Harris 1995; Asche and Steen 1998). To set the context of this paper, the systems of exchange for groundfish species in North Norway are described next.

\section{Exchange Methods Used at Ex-vessel Sale of Fish}

Two methods of exchange dominate the sale of fish: auctions and direct (or contract) sales. Traditionally, auctions have been used in regions where a sufficient number of buyers can congregate to compete, through price bids, for the fish landed. Fish purchased may be sold fresh or be further processed for sale either locally, or more commonly, outside the region. In regions using direct sales, the catch is often processed into salted, dried, or frozen products that can be stored for a longer time.

In most fish auctions around the world, the traditional method is to bring the catch to an auction building where it is graded prior to sale according to specified criteria, including: species, size, and quality. Before selling by auction, the catch is commonly divided into smaller units based upon fish of a given species, size, and quality grade, making it easier for processors to specialise in particular products. In the auction system studied in this paper, frozen graded fish are placed in neutral (commercial) frozen storage. The fishermen's sales organization (Norges Råfisklag) then presents the fish via an electronic or telephone auction. More recently, the same 
sales organisation has also started fresh fish auctions on a trial basis; however, these are not included in this paper. By using auctions, the processors can access more stable raw material supplies because catches from a larger range of vessels can be aggregated, compared to a situation where the processor has to negotiate to buy fish from individual vessels.

Through advances in Information and Communications Technology (ICT), it is now possible to connect several auctions in one system of exchange, thereby enabling remote bidding, as found in Iceland (Arnarson and Trondsen 1998). Completely remote auctions also exist for pelagic fish in Norway and groundfish (demersal/whitefish) in North-West Norway, as described in Armstrong (2001), where the fresh catch is auctioned whilst still onboard the vessel. In North Norway the traditional and still dominant exchange method is direct sale, but for a number of years some fish, mainly frozen, has also been sold by auction. Given the existence of these different systems of exchange and the aforementioned importance of the price obtained for catch, it seems logical to consider whether there are any differences in the prices realised for fish under different systems.

\section{Existing Literature for Price Differences between Auctions and Direct Sales}

The importance of relative bargaining power is probably one reason why auctions are not more widespread worldwide; many fisheries take place in scarcely populated regions where buyers are often few and isolated. Another explanation is the seasonality of many fisheries, which causes large quantities to be landed within a short period of time and, conversely, low or no quantities for a long time. A few articles have compared ex-vessel prices achieved through auctions and direct sales. The case of Iceland has been considered by Arnarson and Trondsen (1998). Matthiasson and Valsson (2000) suggest that possible reasons for the price difference in Iceland include the vertical integration of the fishing industry and the Individual Transferable Quota (ITQ) system. In another study, Trondsen, Helstad, and Young (2003) found the price of fish to be higher at auctions than direct sales in a comparison of regions using auctions (Møre and Romsdal County, Norway, Scotland, and Iceland) and others where direct sales dominated (Iceland and North Norway). Price differences may result simply from perceived differences in the product attributes of the fish sold. Another reason may be the value placed upon the intangible service conferred through the different selling systems. For example, auction sales typically subdivide the catch into more homogeneous lots, thus providing greater scope for buyers to be more selective in the raw material they purchase. This may be especially important where the end product is being manufactured to a tight specification (as is commonly required in consumer markets). In contrast, direct sales tend to require the purchase of a larger volume of product, if not all the quantity landed. This often introduces a more heterogeneous raw material, which produces more varied end products.

Service costs may also vary between the two systems of exchange. Auctions normally require some physical infrastructure in which to display and grade the catch then allocated to buyers. Although as noted, some pelagic fisheries operate on the basis of remote auctions whilst at sea. Direct landings, especially in remote areas, simply supply direct to the buyer's plant. It should also be noted that the aggregation of buyers in itself may tend to influence the price received. According to economic theory, a seller with low relative bargaining power is unlikely to get a high price. Bulow and Klemperer (1996) show that a competitive auction of $N+1$ buyers will give the seller higher expected revenue than would be generated through a monopoly selling position against $N$ buyers. Thus an auction selling system might, 
in the fisheries sector, improve the social efficiency of the sector if the pricing system is combined with restrictions on access to the fisheries; as in the situation of a sole-owner system. Certainly, the presence of more buyers will tend to heighten competition for the fish on sale.

\section{Price Links between Auction and Contract Sales}

The following analysis initially demonstrates the presence of price differences between auction and direct sales of cod and haddock in North Norway, where all vessels in this study have the same fishery management system. Given the homogeneous fisheries management system, this study postulates that observed differences in levels of ex-vessel prices may be explained by differences between the two parallel systems of exchange. The analysis looks at ex-vessel prices for fish as a function of exchange methods in the region by comparing direct sale prices to auction prices. The prices for fish landed (gutted, head-off) between the two exchange methods for cod and haddock landed in North Norway from January 1997 to December 2003 are compared. The price of frozen fish sold by auction is compared to the price of fish sold fresh or frozen by direct sale. The quantity of fresh fish that is auctioned in the period analysed is negligible compared to the other categories, and there are many months where no auctions of fresh fish occur. Because of this, fresh fish sold by auction is not included in the analysis.

Clark and Munro (1980) incorporated a monopolistic processing sector in a dynamic bioeconomic model. One of the results from their analysis was that a processing sector with market power might result in a price system closer to the social optimum. This effect could be countered by fishermen creating a raw fish monopoly. Historically, this is exactly what has happened in the Norwegian fisheries. As we will demonstrate, the recent introduction of auctions has further changed the price level to the benefit of the fishermen. Larkin and Sylvia (1999) developed a model where improved intra-seasonal allocation of a fish resource might increase its value. In the study, the fishing sector was assumed to be vertically integrated and the first-hand price would, thus, only affect the allocation of profit, not the total profit. We assume the fishing sector and the processing sector are independent and make transactions based on either auction prices or regulated spot prices with a minimum floor price that may be binding. The social optimality of the fishing sector is not achieved by means of regulated prices or taxes/subsidies, but by quota regulations and regulation of fishing effort.

Economic theory concerning prices realised under different exchange methods and other empirical evidence analysing the effects of exchange methods, suggests that auction prices will be higher than direct sales prices (Trondsen, Helstad, and Young 2002; Arnarson and Trondsen 1998). The first question will be to establish if there is, in fact, a stable price difference for identical species in the same geographic area for the same period, but traded through the two different systems of exchange: auction and direct sales. This first part is partly descriptive, with the purpose of establishing a basis for the next hypotheses that will be tested formally. The first hypothesis to be tested is whether there are stable, long-run price relationships between the prices revealed through the two exchange methods. To answer this, a bivariate cointegration analysis for the two exchange methods for different sizes of cod and haddock is undertaken. If the prices are cointegrated, a long-run price link exists. If the hypothesis is not rejected, we may then conclude that the price cointegration indicates the presence of LOP. Next, based on the presumption of nonrejection of the first hypothesis, we will test for exogeneity, which are statistical (but not necessarily logical) indications of cause and effect. Tests for weak 
exogeneity will be formulated to find whether the auction price drives the direct sale price in the long run, or vice versa. All formal tests are based on studies of price series. More general equilibrium models intended to explain differences in prices, based on supply and demand functions for each market, have not been investigated in this study.

\section{Ex-vessel Sales of Whitefish in North Norway}

In North Norway the fishermen's sales organisation, Norges Råfisklag (NR), holds the exclusive legal right to organise ex-vessel sales of all groundfish landed in the region (Christensen and Hallenstvedt 1990). The region consists of the counties (from North to South) Finnmark, Troms, Nordland, Nord-Trøndelag, Sør-Trøndelag and part of Møre and Romsdal county, south to the city of Kristiansund. Direct sales predominate, historically in part because of the geography of the region, which consists of many small islands and large fjords requiring fishing vessels to travel relatively long distances between local buyers. Also, the fisheries are highly seasonal and the region is sparsely populated. Before the introduction of laws leading to the establishment of NR, local buyers regularly developed local monopolies, taking advantage of the difficult negotiating position of the local fishermen. Following the legal change, NR was empowered to set the business rules for ex-vessel sales of whitefish in the area, including a minimum legal price for each species, size, and area. In addition, NR certifies fish buyers and guarantees that fishermen get their payment for the catch. The minimum price is agreed upon in negotiations with representatives for the buyers. This minimum price is valid both at the auctions and for direct sales and is set at a level intended to secure some profitability for both buyer and seller (Christensen and Hallenstvedt 1990). To facilitate sales, NR may help fishermen to contact buyers in the region or sell the catch at the NR-organised auctions.

For some years, NR has organised an auction primarily for frozen fish in the region. Frozen fish is auctioned either from a cold store or prior to landing of the frozen-at-sea (FAS) catch. Fish auctioned from a cold store may be divided into smaller, more homogeneous units of species, size, and quality. Buyers incur the cost of transport from the cold store to the processing plant, whereas fish bought from the boat will be discharged directly at the plant.

Unlike a conventional shout auction, NR sends product details and the name of the fishing vessel to prospective buyers who are invited to return bids by fax within a specified time period; NR then attempts to raise bids by telephone. It is mainly the larger trawlers and auto-long-liners that sell their catch at auction (Norges Råfisklag 2001). The same standard fees are charged for the auction and landing elsewhere in the region. The costs of unloading and storing the catch average about $0.30 \mathrm{NOK}$ per kilo landed, or $0.20 \mathrm{NOK} / \mathrm{kg}$ live weight. Having ascertained the organisational structure of the exchange process, this analysis is next directed to any price differences between the two exchange methods and whether there are any long-run, stable relationships in the fish prices commanded.

\section{Landings of Cod and Haddock in North Norway, 1997-2003}

The analysis is based on monthly data of landings of cod and haddock in North Norway from NR over the seven-year period January 1997 to December 2003. The disaggregated data include species size, form (fresh or frozen), and the exchange method for fish landed gutted, head-off. These landings accounted for an average of 
about $87 \%$ and $65 \%$ of total yearly landings of cod and haddock, respectively, during this period. The remaining fish were landed in other forms, such as fillets; whole, or gutted, head-on. The size grading used in the analysis is identical to the one used by NR to set minimum legal prices, and the three size categories for live weight cod are $<1.5,1.5-3.8$, and $>3.8 \mathrm{~kg}$. Haddock is divided into two categories: above and below $1.1 \mathrm{~kg}$. Prices in the analysis are calculated in live weight equivalents (LWE). Average monthly landings of the two species according to size, exchange method, and product form landed for the period 1997-2003 are presented in table 1 .

Table 1 shows that direct sales of fresh fish are the dominant exchange method for most size categories, especially for large fish. For frozen fish, direct sales are important for medium and particularly small fish. For fish sold by direct sale, both cod and haddock, an increasing proportion of landings were landed frozen. One explanation for this is a well-documented switch in foreign landings of Russian boats from fresh to frozen fish. The proportion of cod landings sold at auction relative to total landings is quite stable during the period analysed. For haddock, on the other hand, sales at auctions have declined both absolutely and relatively. There has been a decrease in fish sold fresh for both species.

The variation in the monthly volume landed differs between the three exchange categories. For large cod, direct fresh sales have the largest percentage variation in landed quantity during the year, followed by auction sales of frozen cod. Direct sales of frozen cod have the smallest percentage variation in quantity during the year. The landing pattern is different for medium and small cod, where auction sales in most years have the largest variation, followed by fresh fish at direct sale. A reason for the difference between large and smaller cod is that Norwegian coastal vessels catch large cod migrating to and from the spawning grounds. The remaining fleet, especially trawlers, catch more immature fish on the feeding grounds throughout the year. When analysing the haddock landings pattern, the percentage variation between the different landing conditions is smaller than for cod. A reason for the differences between species may be the greater importance of cod (especially large), in relation to all landings, and because of the large proportion of landings which come from the coastal fleet.

The description above shows large variations in the quantity landed of the two species between both the different exchange methods and product forms. Next, the analysis turns to the possible price links between the two species and the exchange methods for the same period as before.

\section{Monthly Prices for Different Sizes, Product Forms, and Exchange Methods}

Cod is the most commercially important species in the area, and table 2 and figures 1 and 2 show monthly live weight prices of the three different sizes of cod as a function of exchange method and whether landed fresh or frozen.

Figure 1 shows that the price of cod increased during the period analysed for all exchange methods and that price increased as a function of the fish size. In 2001, the price of cod stabilised, then began to decrease. In all categories, prices are highest from September into April, peaking in November and March. Auctions realised the highest prices in all categories in most of the months, whereas fresh cod sold directly got the lowest price in most months. The smaller monthly variations in direct sale prices for fresh cod, compared to the two other categories, may be because a greater quantity of cod is landed fresh and sold by direct sale and consequently has a more stable price pattern. Another reason for this may be that that fresh fish at direct sale gets the lowest price, the minimum legal price, and so acts as a floor price. In 


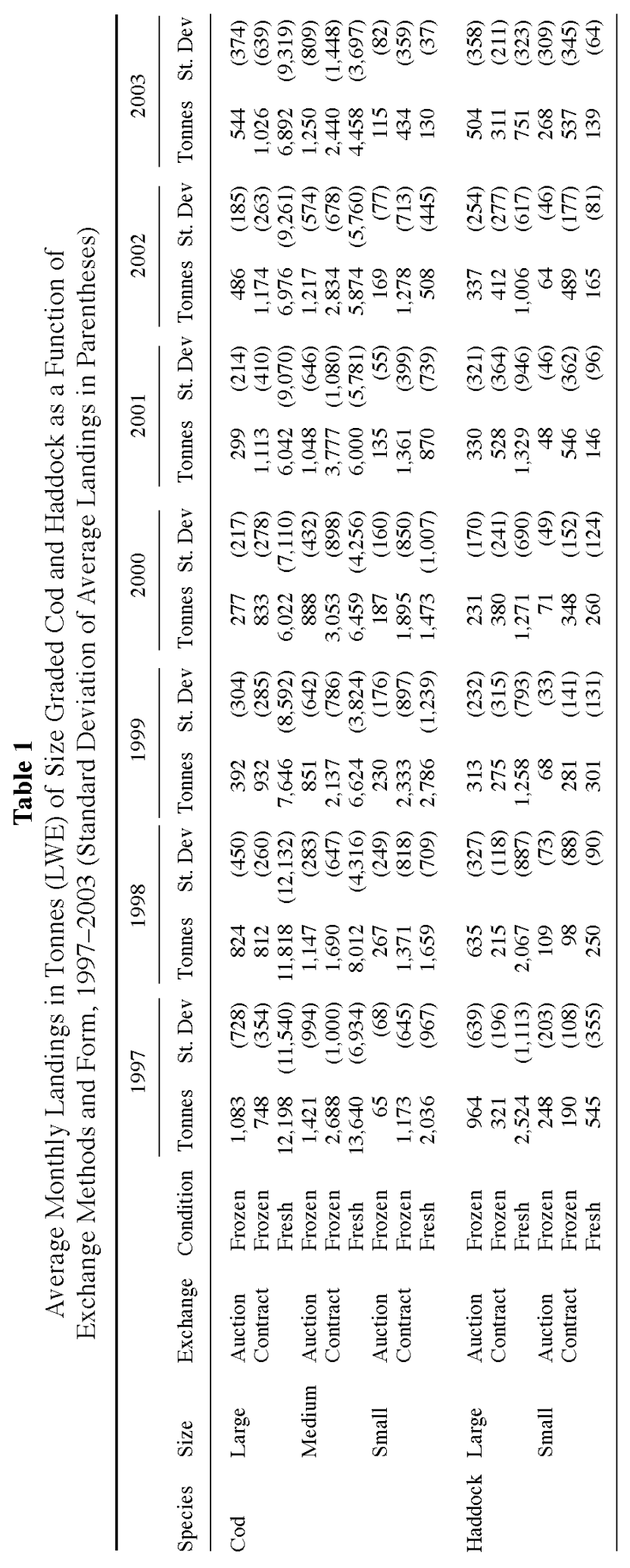




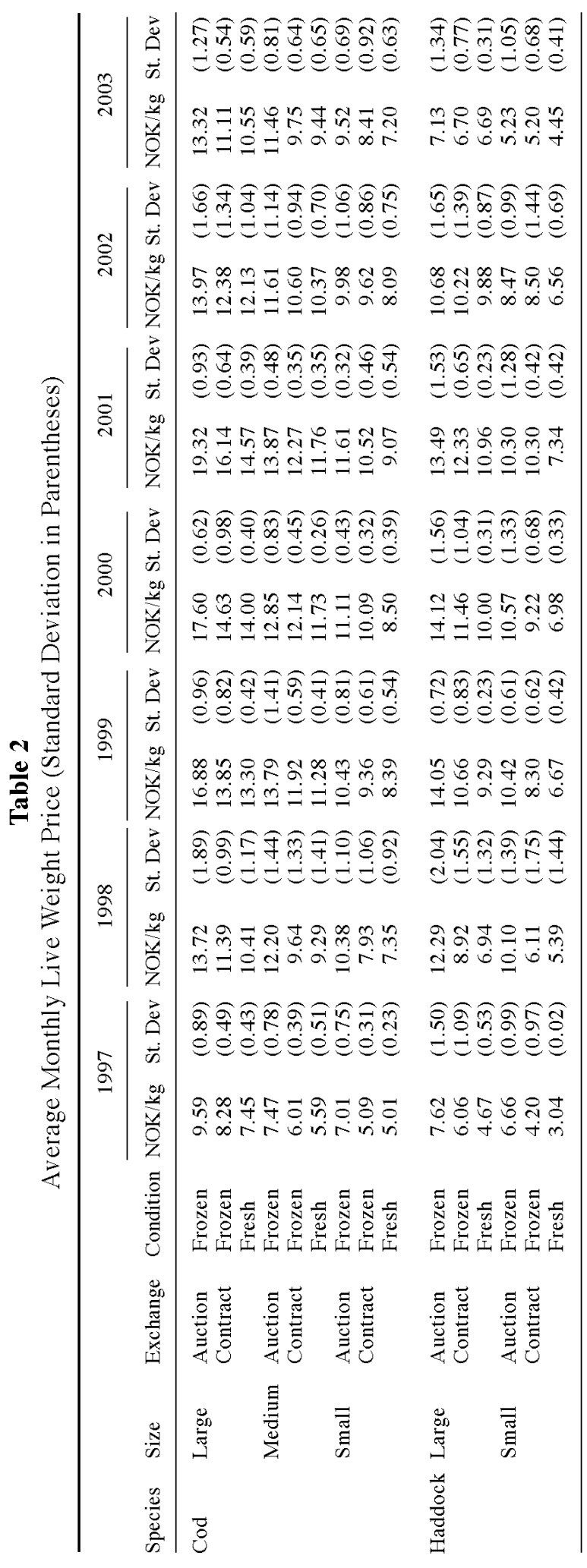



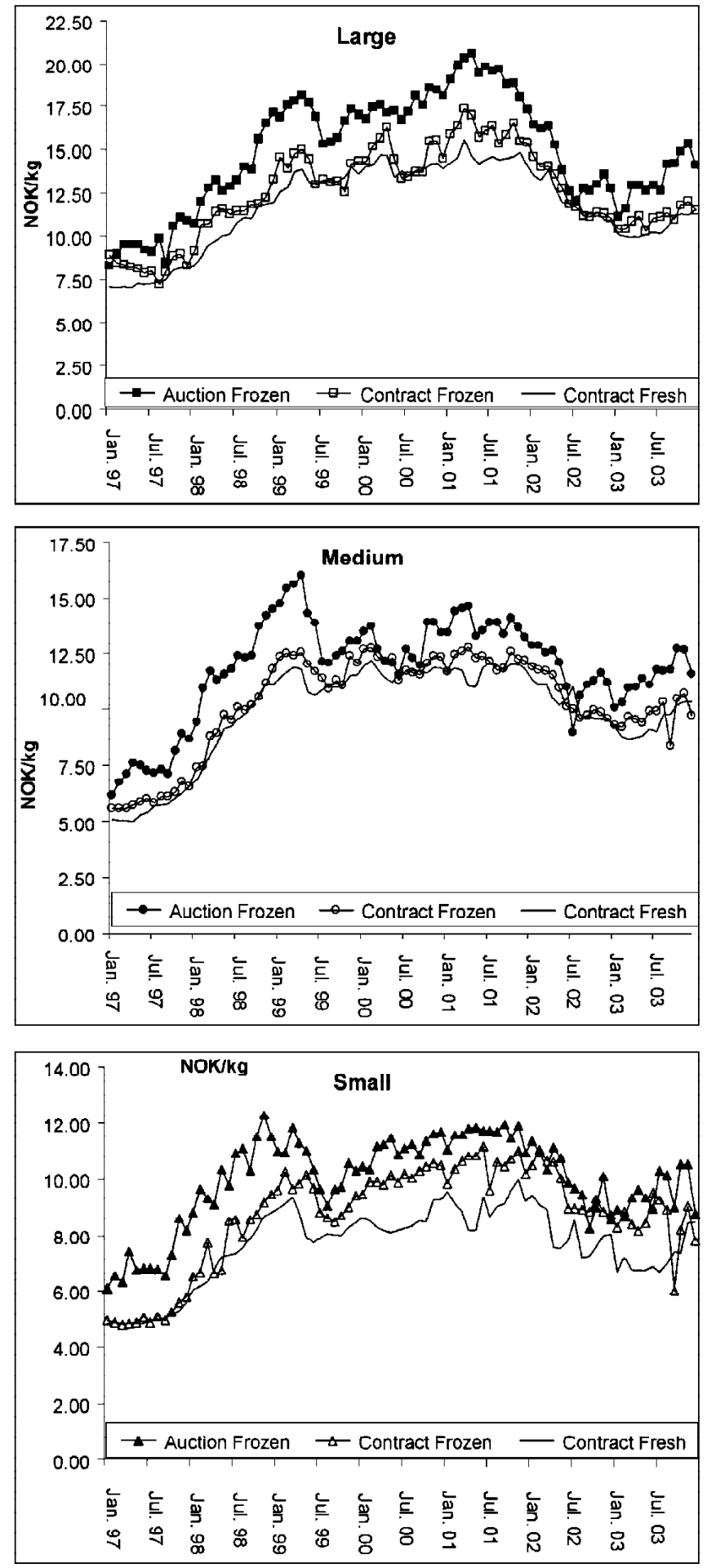

Figure 1. Live Weight Price of Large, Medium, and Small Cod Sold Fresh and Frozen at Direct Sale and Frozen at Auction on a Monthly Basis: January 1997-December 2003 

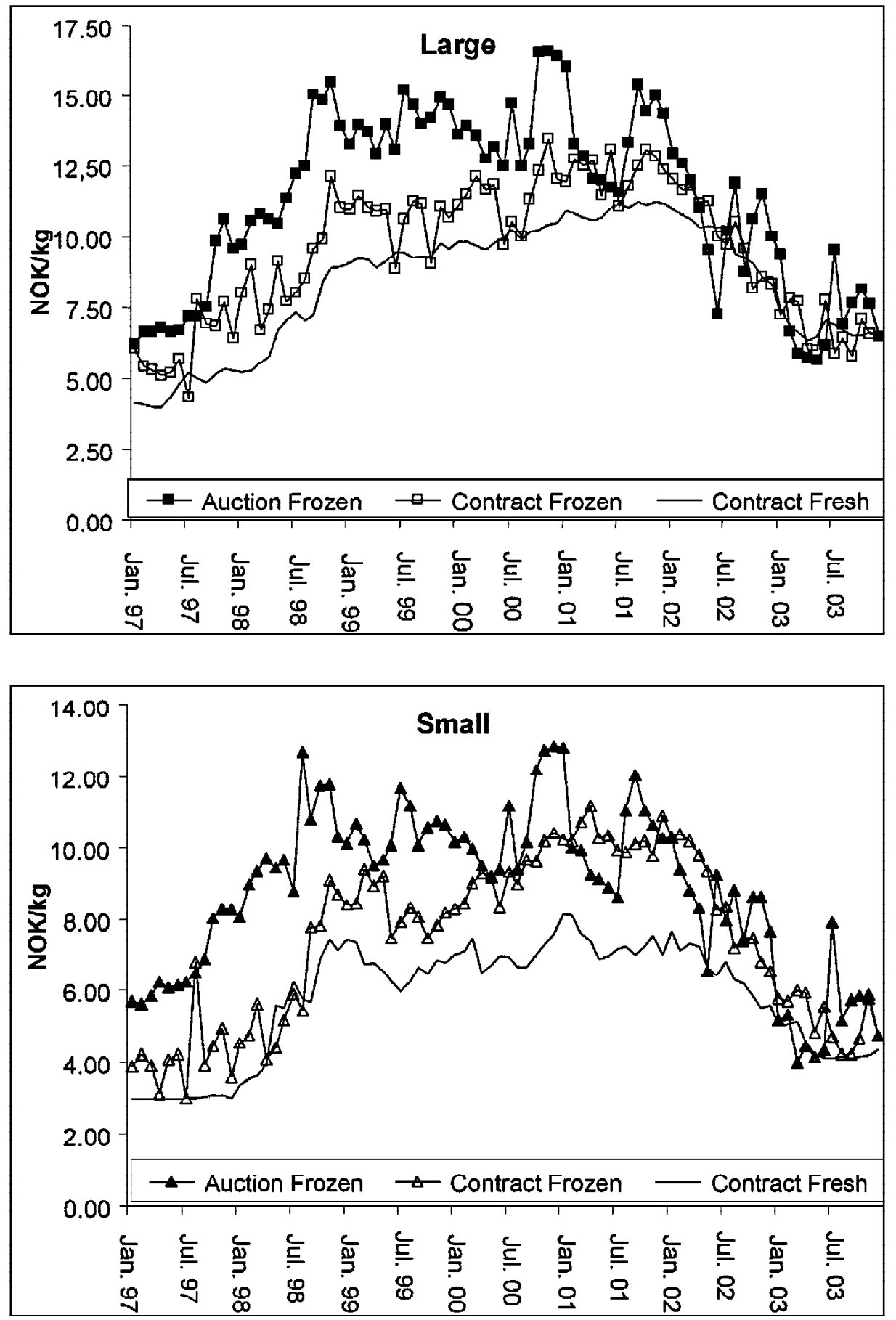

Figure 2. Live Weight Price of Large and Small Haddock Sold Fresh and Frozen at Direct Sale and Frozen at Auction on a Monthly Basis: January 1997-December 2003 
figure 2, the prices of haddock for the two size categories are shown according to exchange method and whether the catch is landed fresh or frozen.

Figure 2 shows an increase in the price of haddock until late 1998, after which it stabilises until a decline in 2002. The price pattern for the different exchange methods for haddock shows a similar trend to that described for cod, having the highest price for frozen haddock at auction and lowest for fresh at direct sale in most months.

Based on the observed price relations and landing patterns over this seven-year period in North Norway, the analysis will next consider price differences between the two exchange methods and if there is a long-run relationship between the different exchange systems and frozen and fresh product forms.

\section{Price Links between Auction and Direct Sale Systems}

The figures presented earlier show price differences between the two exchange systems and that prices fluctuate during the period. The following will test for market integration between the two exchange systems by using cointegration analysis. Monthly ex-vessel prices in the period January 1997-December 2003 (84 observations) are considered. All prices were transformed into the natural logarithm before the cointegration analysis was conducted.

\section{Tests of Stationarity}

The first step in the analysis of statistical relationships between the two exchange methods is to determine whether or not the time series data are stationary. This was done using two alternative versions of the Augmented Dickey-Fuller (ADF) test model. The first version includes a constant only; the second version includes both a constant and a trend coefficient. The ADF is based on the regression equations shown in equation (1), where both the constant and a time trend are included:

$$
\Delta X_{t}=\beta_{0}+\beta_{1} \cdot t+(\rho-1) X_{t-1}+\sum_{\gamma=1}^{k} b_{\gamma} \Delta X_{t-\gamma}+u_{t},
$$

where $\Delta$ is the difference operator, $\beta_{0}$ is a constant term, and $\beta_{1}$ is a time trend term (Dickey and Fuller 1979). The null hypothesis, $\left(\mathrm{H}_{0}\right)$, in the test is that the time series is non-stationary, $\rho=1$, against the opposite, $\left(\mathrm{H}_{1}\right)$, stationarity, $\rho<1$.

The ADF-t test statistics differ from the normal $t$ statistics. Critical values are calculated using the MacKinnon (1991) response surface estimates (Maddala and Kim 1998). A lag length of 4 was used in the ADF test at level and a lag length of 3 at first difference. The results are shown in table 3.

Table 3 shows that all prices are non-stationary with or without a trend included at the 5\% significance level, except for medium fresh cod via direct sale with a constant. The test of the time series at first difference shows that the first difference is stationary for all time series at the selected lag length of 3. Inclusion of a time trend does not change the picture. According to Gordon (1995) and Gordon and Hannesson (1996), the power of the test to reject the null hypothesis of nonstationarity decreases when the number of lags is increased. When experimenting with shorter lag lengths, the results were consistent with the results described above. 
Table 3

Augmented Dickey-Fuller t-test Statistics ADF

\begin{tabular}{|c|c|c|c|c|c|c|c|}
\hline \multirow[t]{2}{*}{ Species } & \multirow[t]{2}{*}{ Size } & \multirow[t]{2}{*}{ Exchange } & \multirow[t]{2}{*}{ Condition } & \multicolumn{2}{|c|}{ Price Levels } & \multicolumn{2}{|c|}{ First Difference } \\
\hline & & & & Constant & Trend & Constant & Trend \\
\hline \multirow[t]{9}{*}{ Cod } & \multirow[t]{3}{*}{ Large } & Auction & Frozen & -2.085 & -1.687 & $-5.077^{* *}$ & $-5.454^{* *}$ \\
\hline & & \multirow[t]{2}{*}{ Direct } & Frozen & -2.323 & -1.847 & $-4.661^{* *}$ & $-5.042^{* *}$ \\
\hline & & & Fresh & -2.425 & -1.996 & $-3.974^{* * *}$ & $-4.702^{* *}$ \\
\hline & \multirow[t]{3}{*}{ Medium } & Auction & Frozen & -2.625 & -2.235 & $-4.758^{* *}$ & $-5.148^{* *}$ \\
\hline & & \multirow[t]{2}{*}{ Direct } & Frozen & -2.712 & -2.128 & $-3.983^{* *}$ & $-4.639^{* *}$ \\
\hline & & & Fresh & $-3.057^{*}$ & -2.647 & $-3.472^{*}$ & $-4.073^{* *}$ \\
\hline & \multirow[t]{3}{*}{ Small } & Auction & Frozen & -2.616 & -2.168 & $-3.839^{* *}$ & $-4.253^{\text {** }}$ \\
\hline & & Direct & Frozen & -2.832 & -1.272 & $-6.324^{* *}$ & $-7.456^{* *}$ \\
\hline & & & Fresh & -2.615 & -2.320 & $-5.231^{* *}$ & $-5.471^{* *}$ \\
\hline \multirow[t]{6}{*}{ Haddock } & \multirow[t]{3}{*}{ Large } & Auction & Frozen & -7.750 & -2.089 & $-4.731^{* *}$ & $-5.116^{* *}$ \\
\hline & & Direct & Frozen & -2.033 & -1.434 & $-6.294^{* *}$ & $-7.431^{* *}$ \\
\hline & & & Fresh & -2.040 & -0.811 & $-4.253^{* * *}$ & $-5.813^{* *}$ \\
\hline & \multirow[t]{3}{*}{ Small } & Auction & Frozen & -1.416 & -2.048 & $-5.293^{* *}$ & $-5.622^{* *}$ \\
\hline & & Direct & Frozen & -1.994 & -1.069 & $-5.224^{* *}$ & $-5.961^{* *}$ \\
\hline & & & Fresh & -2.185 & -1.483 & $-3.804^{* * *}$ & $-4.432^{* *}$ \\
\hline
\end{tabular}

Notes: Level lag $=4$; First Difference lag $=3$.

*A constant is included in the ADF-model. ${ }^{* *}$ A constant and a trend are included in the ADF-model.

\section{Results of the Tests for Price Linkages between Auction and Direct Sale}

Two or more time series, each integrated to the order 1, I(1), are cointegrated if a linear combination of the time series that is $\mathrm{I}(0)$, exists. The time series $X_{t}$ and $Y_{t}$, each $\mathrm{I}(1)$, in equation (2) where $\gamma$ is the cointegration vector, is cointegrated if the error term, $u_{t}$, is stationary, $\mathrm{I}(0)$ :

$$
u_{t}=Y_{t}-\gamma X_{t} .
$$

This means that a long-run relationship exists between the time series even if the series themselves contain stochastic trends. Variables that are stationary in levels, $\mathrm{I}(0)$, should not be included in the cointegration analysis.

We used the Johansen-Juselius procedure for testing cointegration between two time series, $t$ (Johansen 1988; Johansen and Juselius 1990). This tests for presence of cointegration in a Vector Autoregression (VAR) model. The formal presentation of the method is well covered in both textbooks and articles, and need not be repeated here.

The method identifies the number of independent cointegration vectors, $r$; if $r=0$, there is no cointegration. In our bivariate analysis there may be a maximum of one cointegration vector, meaning that $r$ can become 1 as maximum. The Trace-test and the asymptotically equivalent Maximum Eigenvalue Test (Max Test), which tests the null hypothesis of $r=0$ cointegration vectors versus the hypothesis of $r>0$ cointegration vectors, are used. The analysis reports on both tests. The results of the test of cointegration between auctions and direct sales in North Norway are presented in table 4, which contains the test results calculated using the Max Test and 
Table 4

Bivariate Cointegration Test of Price of Fish Sold Fresh or Frozen by Direct Sale against Frozen Sold at Auction

\begin{tabular}{|c|c|c|c|c|c|c|}
\hline \multirow[b]{2}{*}{ Species } & \multirow[b]{2}{*}{ Size } & \multirow[b]{2}{*}{ Condition } & \multicolumn{2}{|c|}{$\begin{array}{c}\text { Max Test } \\
\mathrm{H}_{0}: \text { Rank }=r\end{array}$} & \multicolumn{2}{|c|}{$\begin{array}{c}\text { Trace Test } \\
\mathrm{H}_{0}: \operatorname{Rank}=r\end{array}$} \\
\hline & & & $r=0$ & $r \leq 1$ & $r=0$ & $r \leq 1$ \\
\hline \multirow[t]{6}{*}{ Cod } & \multirow[t]{2}{*}{ Large } & Frozen & $27.73^{* *}$ & 5.16 & $32.89^{* * *}$ & 5.16 \\
\hline & & Fresh & $27.60^{* * *}$ & 4.54 & $32.13^{* * *}$ & 4.54 \\
\hline & \multirow[t]{2}{*}{ Medium } & Frozen & $19.94^{*}$ & 8.05 & $27.98^{* *}$ & 8.05 \\
\hline & & Fresh & $20.10^{*}$ & 8.88 & $28.98^{* * *}$ & 8.88 \\
\hline & \multirow[t]{2}{*}{ Small } & Frozen & $22.23^{* * *}$ & 9.18 & $31.41^{* * *}$ & 9.18 \\
\hline & & Fresh & $22.10^{\text {*** }}$ & $9.53^{*}$ & $31.62^{* * *}$ & $9.53^{*}$ \\
\hline \multirow[t]{4}{*}{ Haddock } & \multirow[t]{2}{*}{ Large } & Frozen & $19.84^{*}$ & 2.76 & $22.59^{*}$ & 2.76 \\
\hline & & Fresh & $16.06^{*}$ & 3.29 & 19.34 & 3.29 \\
\hline & \multirow[t]{2}{*}{ Small } & Frozen & $18.43^{*}$ & 2.14 & $20.57^{*}$ & 2.14 \\
\hline & & Fresh & $19.26^{*}$ & 2.52 & $21.77^{*}$ & 2.52 \\
\hline
\end{tabular}

$\operatorname{Lag}=3 ;{ }^{* *} 1 \%$ and ${ }^{*} 5 \%$.

Trace tests, respectively. A lag length of 3 was used and a restricted constant was included in the analysis.

Table 4 shows that both the Max test and Trace test do not reject the hypothesis of maximum one cointegration vector (rank $£ 1$ ) at the $5 \%$ level for all species and size categories analysed, with the exception of medium fresh cod. The results of the test of no cointegration vector, $(r=0)$, is consistent between the Trace and Max test. Only in the case of small frozen haddock the tests do not reject the hypothesis of no cointegration vector $(r=0)$ between direct and auction sales at the $5 \%$ level. The two tests are asymptotically equal. The time series are considered to be cointegrated if at least one of the tests indicates cointegration. In so doing, a weaker degree of cointegration is accepted than Johansen and Juselius (1990), who recommend the Max test because the Trace test tends to accept cointegration too often. In the following, we treat the time series as cointegrated if one of the tests indicates cointegration.

Using the results of the Max test, the results show the prices of frozen cod sold at auction to be cointegrated for all size categories of cod sold direct, both fresh and frozen. Haddock is slightly less cointegrated than cod. Fresh, large haddock is not cointegrated with auctioned haddock using the Trace test, and no combinations are cointegrated at the $1 \%$ level.

\section{Tests for Law of One Price and Weak Exogeneity}

According to Stiegler (1969), goods can be said to be in the same market if they make a stable, long-run relationship, LOP, as shown in the equation below:

$$
\ln p_{t}^{1}=\delta+\phi \ln p_{t}^{2}
$$

where $p^{1}$ and $p^{2}$ is the price of goods 1 and 2, respectively. 
In the strict version of the LOP, $\delta=0$ and $\phi=1$ and the prices are equal, while if $\delta \neq 0$ and $\phi=1$, their levels differ due to factors such as transportation costs and quality differences.

For non-stationary time series, it is not possible to test for presence of LOP by making a regression and then testing for $\phi=1$. The Johansen test allows for testing of the presence of proportionality between the variables in the long run and for nonstationary time series by introducing restrictions of the variable $\beta$ using a likelihood ratio test (Johansen and Juselius 1990). For the LOP hypothesis to hold on non-stationary time series, it is equivalent to testing whether $\beta=(1,-1)$ in the bivariate case for cointegrated time series. A cointegration relationship between goods indicates co-movement of the prices and is a less restrictive definition of market integration than LOP.

The next stage is to test for the presence of LOP and weak exogeneity for the cointegrated prices, including the weakly cointegrated time series. Table 5 shows the results of the test for the presence of LOP and weak exogeneity for the price combinations analysed. The test statistics are $\chi^{2}$ distributed, with a degree of freedom of 1 .

Table 5 shows a strong price link between auction and direct sales prices as the LOP is accepted for all sizes analysed except for large cod, both fresh and frozen, where the hypothesis of LOP is rejected at the 5\% level. The results are in accordance with the results from the bivariate cointegration tests.

By using restrictions of the $\alpha$ in the Johansen test (Johansen and Juselius 1990), a test for weak exogeneity for each of the variables included in the analysis can be done using a likelihood ratio test. We test if the price of product $i$ drives the price of product $j$. If the null-hypothesis, $\mathrm{H}_{0}: \alpha=0$, is not rejected, the variable $i$ is exogenous. The test is then to analyse if one of the prices drives the other in the long run.

The hypothesis of weak exogeneity for the auction prices is not rejected at the $5 \%$ level for any of the comparisons made. The hypothesis of weak exogeneity is rejected for all of the analyses at the 5\% level for the direct sales prices. Consequently, this indicates that the direct sale prices of frozen fish are driven by the auction prices in the long run.

Table 5

Test of Presence of LOP and Weak Exogeneity (P-value in Parentheses)

\begin{tabular}{|c|c|c|c|c|c|c|c|c|}
\hline \multirow{3}{*}{$\frac{\text { Species }}{\text { Cod }}$} & \multirow{3}{*}{$\frac{\text { Size }}{\text { Large }}$} & \multirow{3}{*}{$\begin{array}{c}\text { Condition } \\
\text { Frozen }\end{array}$} & & & \multicolumn{4}{|c|}{ Weak Exogeneity } \\
\hline & & & \multicolumn{2}{|c|}{ LOP } & \multicolumn{2}{|c|}{ Price 1: Auction } & \multicolumn{2}{|c|}{ Price 1: Direct } \\
\hline & & & $4.11^{*}$ & $-(0.04)$ & 0.04 & $(0.83)$ & $18.96^{* *}$ & $(0.00)$ \\
\hline & & Fresh & $4.08^{*}$ & $-(0.04)$ & 0.38 & $(0.54)$ & $15.78^{* *}$ & $(0.00)$ \\
\hline & Medium & Frozen & 0.83 & $-(0.36)$ & 0.00 & $(0.98)$ & $8.51^{* *}$ & $(0.00)$ \\
\hline & & Fresh & 0.25 & $-(0.62)$ & 2.05 & $(0.15)$ & $8.68^{* *}$ & $(0.00)$ \\
\hline & Small & Frozen & 1.38 & $-(0.24)$ & 1.65 & $(0.20)$ & $13.05^{* *}$ & $(0.00)$ \\
\hline & & Fresh & 0.03 & $-(0.87)$ & 0.19 & $(0.66)$ & $12.55^{* *}$ & $(0.00)$ \\
\hline \multirow{4}{*}{ Haddock } & Large & Frozen & 0.31 & $-(0.58)$ & 0.51 & $(0.48)$ & $15.08^{* *}$ & $(0.00)$ \\
\hline & & Fresh & 0.97 & $-(0.32)$ & 0.55 & $(0.46)$ & $11.31^{* *}$ & $(0.00)$ \\
\hline & Small & Frozen & 2.55 & $-(0.11)$ & 0.35 & $(0.55)$ & $15.73^{* *}$ & $(0.00)$ \\
\hline & & Fresh & 0.89 & $-(0.35)$ & 0.00 & $(0.97)$ & $16.72^{* *}$ & $(0.00)$ \\
\hline
\end{tabular}

Notes: ${ }^{* *} 1 \%$ and ${ }^{*} 5 \%$. 


\section{Discussion and Conclusions}

The analysis clearly shows there are some price differences between fish sold at auction and at direct sales in North Norway. Similarly, there are differences in the prices of frozen fish sold at auction and both fresh and frozen sold by direct sales. For comparable species and size grades, the auction prices are higher. The literature analysing price differences between direct sales and auction sales suggests that exvessel prices of fish sold at auction would exceed direct sales prices (Matthiasson and Valsson 2000; Trondsen, Helstad, and Young 2002). This is reconfirmed in this paper. The cointegration tests for cod showed generally strong price links between auction and direct sales, and the price links were weakest for grades where auction sales are small. The price differences may be due to the different levels of competition for fresh and frozen fish that dominate the two exchange methods. Also, when sold straight from a vessel through direct sale, each batch of fish tends to be larger than when sold at auction. In addition to larger batches, the catch composition may be more heterogeneous both in fish size and species. Thus, there may be both a quantity and a quality effect to explain differences in price levels.

A further contributory factor for at least some of the price differences observed may be because buyers commonly incur unloading and handling charges in direct sales, whereas the fishermen absorb these when selling through auctions. Perhaps more importantly is the fact that larger quantities of fish are sold through direct sales than by auction, and there are larger seasonal variations in landings sold directly, especially for fresh fish.

The species analysed are of great commercial importance in the region, but the cointegration results showed some differences when comparing cod and haddock. In terms of the target market, the EU dominates for both cod and haddock. In previous analyses for price links between several countries, it has been suggested that effectively one market for whitefish exists (Gordon and Hannesson 1996; Asche, Gordon, and Hannesson 2002). This analysis has a more local approach. We have shown that the price relationship, in terms of degree of cointegration, is stronger for frozen fish sold at an outside auction than for frozen fish sold at auctions and fresh fish sold direct. Similarly, there is shown to be a stronger price relationship for cod sold at auction and outside auctions than is the comparable case for haddock. This may well be because frozen fish sold by the two exchange methods are closer substitutes further down the distribution chain than frozen and fresh fish.

We have also demonstrated that for the Norwegian cod and haddock markets, the auction prices for frozen fish will drive the direct sale prices of both frozen and fresh fish - not the other way around - even though the quantity sold via direct sales is larger than that by auctions. In our study, we had no observations from a fresh fish auction market. This absence of a fresh fish auction market may explain our results, which contrast with most other studies of the relationships between fresh fish and frozen fish markets. Other studies show that fresh fish prices are normally higher than frozen and that fresh fish auction prices drive the frozen fish prices and direct sales prices of all kinds of fish (Gordon and Hannesson 1996; Arnarson and Trondsen 1998; Trondsen, Helstad, and Young 2002). Fresh fish are preferred and command higher prices than frozen fish in most markets where consumers can exercise choice (Trondsen 1997a). This has been documented in a number of fisheries around the globe, including the Canadian case of fresh fish trade in individual $\mathrm{Pa}$ cific halibut quotas (Sjøholt 1997), and more commonly in groundfish sold in European auctions and farmed Atlantic salmon exports from Norway and other EU producers (SFIA 2002). Generally, the lack of a supply response to consumer preferences indicates the existence of some barriers to market orientation (Trondsen 1997b). In this particular Norwegian case, one explanation is that the supply barriers 
are related to the existence of frozen fish auctions and the lack of fresh fish auctions that could serve as differentiating price leaders.

The test of weak exogeneity shows that the presence of auctions affects prices realised through direct sales and that auctions open up further possibilities for adding value in the region. Given the conduct of the exchange process, it might also be hypothesised that auction prices are more transparent and send clearer, more frequent signals to the market than do direct sales. If this is so, auction prices are more market informative than the direct sales prices. NR is aware of this positive effect of auctions and intends to increase their use of them in the future, including fresh fish auctions (Myrvang 2003). In doing so, the fishermen's sales monopoly might expect to realise the advantages of a fish auction in the fresh fish value chain, as has already been demonstrated in the frozen fish value chain. Currently, the lack of fresh fish auctions reduces the market signals of consumer preferences and, hence, occludes both the market value of the fishers' catch and consumers' satisfaction with fresh fish supplies.

Although the introduction of fish auction markets has resulted in the efficient transmission of information, an increase in the average level of prices, better allocation of fish through the distribution channel, and possibly improvement in the value adding of the sector, many still oppose them. There are many vested interests in maintaining non-efficient markets (Porter 1980). In addition, legitimate distribution objections may be relevant, and this analysis takes no account of possible local employment effects. Whilst many of these problems belong more in the political arena, rather than the ambit of this article, the findings may help formulate future policy decisions on the adoption of different systems of exchange.

\section{References}

Anderson, L.G. 1986. The Economics of Fisheries Management, Rev. and Enl. Ed., 296 p. Baltimore, MD: Johns Hopkins University Press.

Ardeni, P.G. 1989. Does the Law of One Price Really Hold for Commodity Prices? American Journal of Agricultural Economics 71(August):663-69.

Armstrong, C.W. 2001. Theory and Practice of Why Auctions Differ-A Study of Two Fish Auctions in Norway. Marine Policy 25:209-14.

Arnarson, I., and T. Trondsen. 1998. Value Adding in the First Hand Sales of Fish. A Comparison between Contract- and Auction Market Prices. A Descriptive Analysis of the Icelandic Case. Proceedings of the Ninth Conference of the International Institute of Fisheries Economics and Trade, A. Eide and T. Vassdal, eds., pp. 819-26. Troms $\emptyset$, Norway: IIFET.

Asche, F. 2001. Testing the Effect of an Anti-Dumping Duty: The US Salmon Market. Empirical Economics 26:343-55.

Asche, F., T. Bjorndal, and J.A. Young. 2001. Market Interactions for Aquaculture Products. Aquaculture Economics and Management 5(5/6):303-18.

Asche, F., H. Bremnes, and C.R. Wessells. 1999. Product Aggregation, Market Integration and Relationships between Prices: An Application to World Salmon Markets. American Journal of Agricultural Economics 81(August):568-81.

Asche, F., O. Flaaten, J.R. Isaksen, and T. Vassdal. 2002. Derived Demand and Price Relationships between Prices at Different Levels in the Value Chain: A Note. Journal of Agricultural Economics 53(1):101-7.

Asche, F., D.V. Gordon, and R. Hannesson. 2002. Searching for Price Parity in the European Whitefish Market. Applied Economics 34:1017-24.

Asche, F., K.G. Salvanes, and F. Steen. 1997. Market Delineation and Demand Structure. American Journal of Agricultural Economics 79(1):139-50. 
Asche, F., and F. Steen. 1998. The EU One or Several Fish Markets: An Aggregated Market Delineation Study of the EU Fish Market. SNF-Report: 61/98, 43 p. 12/ 98. Bergen, Norway: SNF.

Bulow, J., and P. Klemperer. 1996. Auctions versus Negotiations. The American Economic Review 86(1):180-94.

Christensen, P., and A. Hallenstvedt. 1990. På Første Hånd: Norges Råfisklag Gjennom Femti År. (in Norwegian), 247 p. Troms $\varnothing$, Norway: Norges Råfisklag.

Clark, C.W. 1990. Mathematical Bioeconomics: The Optimal Management of Renewable Resources, 2nd Ed., 386 p. New York, NY: Wiley.

Clark, C.W., and G.R. Munro. 1980. Fisheries and the Processing Sector: Some Implications for Management Policy. The Bell Journal of Economics 11(2):604-16.

Clayton, P.L., and D.V. Gordon. 1999. From Atlantic to Pacific: Price Links in the US Wild and Farmed Salmon Market. Aquaculture Economics and Management 3(2):93-104.

Dickey, D.A., and W.A. Fuller. 1979. Distribution of the Estimators for Autoregressive Time Series with a Unit Root. Journal of the American Statistical Association 74:427-31.

Dreyer, B., B.I. Bendiksen, A. Iversen, and J.R. Isaksen. 1998. Vertical Integration-Is that the Way to Go? (in Norwegian), 22/98Troms $\varnothing$, Norway: Norwegian Institute of Fisheries and Aquaculture AS.

Gordon, D.V. 1995. Optimal Lag Length in Estimating Dickey-Fuller Statistics: An Empirical Note. Applied Economics Letters 2:188-90.

Gordon, D.V., and R. Hannesson. 1996. On Prices of Fresh and Frozen Cod Fish in European and U.S. Markets. Marine Resource Economics 11:223-38.

Hannesson, R. 1993. Bioeconomic Analysis of Fisheries, 138 p. Oxford, UK: Fishing News Books.

Harris, R.I.D. 1995. Using Cointegration Analysis in Econometric Modelling . Hemmel Hempstead, Hertfordshire, UK: Prentice Hall-Harvester Wheatsheaf.

Jaffry, S.A., S. Pascoe, and C. Robinson, 1999. Long Run Price Flexibilities for High Valued UK Fish Species: A Cointegration Systems Approach. Applied Economics (31):473-81.

Johansen, S. 1988. Statistical Analysis of Cointegration Vectors. Journal of Economic Dynamics and Control 12:169-210.

Johansen, S., and K. Juselius. 1990. Maximum Likelihood Estimation and Interference on Cointegration - with Applications to the Demand for Money. Oxford Bulletin of Economics and Statistics 52(2):169-210.

Larkin, S.L, and G. Sylvia. 1999. Intrinsic Fish Characteristics and Intraseason Production Efficiency: A Management-Level Bioeconomic Analysis of a Commercial Fishery. American Journal of Agricultural Economics 81(1):29-43.

MacKinnon, J.G. 1991. Critical Values for Co-Integration Tests. Long-Run Economic Relationships, R.F. Engle and C.W. J. Granger, eds., pp. 267-76. Oxford, UK: Oxford University Press.

Maddala, G.S., and I.-M. Kim. 1998. Unit Roots, Cointegration and Structural Change. Themes in Modern Econometrics. Cambridge, UK: Cambridge University Press.

Matthiasson, T., and B. Valsson. 2000. Ex-vessel Price of Cod in Iceland. Empirical and Contract-Theoretical Consideration. Microbehavior and Macroresults: Proceedings of the Tenth Biennial Conference of the International Institute of Fisheries Economics and Trade, R.S. Johnston and A.L. Shriver, eds. Corvallis, OR: IIFET.

Muscatelli, V.A., and S. Hurn. 1992. Cointegration and Dynamic Time Series Models. Journal of Economic Surveys 6(1):1-43. 
Myrvang, T. 2003. Norges Råfisklag, Tromso, Norway, personal communication. March 14.

Norges Råfisklag. 2001. Årsberetning 2000 (in Norwegian), 54 p.

Ottesen, G.G., and K. Grønhaug. 2002. Market Orientation and Uncertain Supply in Upstream Markets: An Exploratory Study. European Journal of Purchasing \& Supply Management 8:209-19.

Porter, M.E. 1980. Competitive Strategy: Techniques for Analyzing Industries and Competitors, 396 p. New York, NY: The Free Press.

SFIA. 2002. European Supplies Bulletin 22(1):189. Edinburgh, Scotland: Sea Fish Industry Authority.

Sjøholt, T. 1997. Innføring Av Et Nytt Reguleringsregime For Kveitefisket I Alaska, Og Dets Innvirkning I Kveitemarkedet. Master thesis, (in Norwegian) Norwegian College of Fisheries Sciences, University of Troms $\varnothing$, Norway.

Stiegler, G.J. 1969. The Theory of Price. London, UK: Macmillan Company.

Trondsen, T. 1997a. Marketing Potential and Barriers for Fresh Packed Fish. A Survey of Buyer Perception in UK and French Seafood Distribution. Journal of Food Products Marketing 4(2):79-99.

. 1997b. Value-Added Fresh Seafood. Barriers to Growth. Journal of International Food \& Agribusiness Marketing 8(4):55-78.

Trondsen, T., K. Helstad, and J.A. Young. 2002. Exchange Method and Catch Value. A Comparative Analysis of Ex-Vessel Prices in Scotland, Iceland and Norway 1990-1999. Mimeo, 30 p. Norwegian College of Fisheries Sciences, University of Troms $\varnothing$, Norway.

. 2003. Market-Oriented Regional Fisheries Management - An Analysis of Four Fish Regions in the North Atlantic. Ocean \& Coastal Management 46:917-41.

Trondsen, T., and R. Johnston. 1998. Market Orientation and Raw Material Control. Journal of Market Focused Management 3:193-210. 